\title{
Metadiscourse in academic writing: A comparison of research articles and book reviews
}

\author{
Betül Bal-Gezegin a* (D), Melike Baş b \\ a Ondokuz Mayıs University, Samsun, Turkey \\ ${ }_{b}$ Amasya University, Amasya, Turkey \\ Received 3 March 2019 | Received in revised form 15 May 2019 | Accepted 23 June 2019
}

\section{APA Citation:}

Bal-Gezegin, B., \& Baş, M. (2020). Metadiscourse in academic writing: A comparison of research articles and book reviews. Eurasian Journal of Applied Linguistics, 6(1), 45-62.

Doi: 10.32601/ejal.710204

\begin{abstract}
The aim of this comparative study is to investigate the deployment of interactional metadiscourse features in two different academic genres. For this purpose, a small, specialized corpus of 48 research articles and book reviews from seven different disciplines were collected. The conclusion sections of the texts written by non-native speakers of English were investigated to find out how interactional metadiscourse features were used. Drawing on previous metadiscourse frameworks, hedges, boosters, attitude markers, self-mentions and engagement markers were identified in both sub-corpora. The results indicated significant differences across the groups on how writers constructed their authorial stance with interactional metadiscourse markers. Findings revealed that by using a rich number and variety of attitude markers, book reviewers were more evaluative in their conclusions. On the contrary, higher use of hedges in research articles allowed the authors sound more cautious in their commitment to the propositions. This study offers a detailed account of interactional metadiscourse in these two genres and illustrates how interpersonal function of language is accomplished for particular purposes in different academic texts.
\end{abstract}

(C) 2020 EJAL \& the Authors. Published by Eurasian Journal of Applied Linguistics (EJAL). This is an open-access article distributed under the terms and conditions of the Creative Commons Attribution license (CC BY-NC-ND) (http://creativecommons.org/licenses/by-nc-nd/4.0/).

Keywords: Book review; corpus; genre; metadiscourse; research articles

\footnotetext{
* Corresponding author

E-mail address: betul.balgezegin@omu.edu.tr http://dx.doi.org/10.32601/ejal.710204
} 


\section{Introduction}

Metadiscourse refers to "the interpersonal resources used to organize a discourse or the writer's stance toward either its content or the reader" (Hyland, 2000, p. 109). It covers a variety of linguistic features that writers employ to frame their arguments to the needs and expectations of their readers so that the readers can create a bond with the text and interpret it in the way writers desire. The notion of metadiscourse relies on the belief that the ultimate meaning of a text is gathered from the interaction of its constituent parts, still it is important to identify the ideational content of the text from elements that organize this content and deliver the writer's views and attitudes toward it (Hyland \& Tse, 2004).

In his 2001 work, Thompson distinguishes two major types of interaction in written texts, which later is developed by Hyland (2004), that is, interactive and interactional. The interactive type concerns the organization of the information, and the coherence of the propositional content, hence aims to guide readers through the content of the text via the features of transitions, frame markers, endophoric markers, evidentials and code glosses. The interactional type, on the other hand, involves the readers in the argument or spirit of the text, and to comment on their message. For this purpose, the writers try to construct an interaction with their audiences and indicate their perspective towards the propositional content through certain linguistic devices (Hyland, 2004).

Interactional dimension of metadiscourse, as proposed by Hyland deals with reader's involvement in the text, and 'the writer's efforts to control the level of personality in a text and establish a suitable relationship to his or her data, arguments, and audience" (2004, p. 139). This aspect shows the reader-author interaction in the texts, which is carried out by particular devices (i.e. hedges, boosters, attitude markers, engagement markers, and self-mentions) employed by authors to express their point of view, focus reader's attention, position themselves and create a dialogue with the reader. The significance of the interactional dimension of writing is that it shows how a text can be constructed communicatively according to the needs of readers by creating a cooperative space for them. This study concentrates on the interactional plane since it aims to investigate the authorial stance in academic writing in different genres. Genre, here is defined as "a term for grouping texts together, representing how writers typically use language to respond to recurring situations" (Hyland, 2004, p. 87) and is used synonymously with text type in this paper.

Metadiscourse is an essential component of academic writing. The study of academic discourse is a relatively young field; however, its significance in research and educational settings as well as how it diverges across genres and disciplines have recently drawn the attention of linguists in parallel with the increase of corpus-based studies. Academic writing includes various text types from textbooks to research articles, each of which has its own way of interacting with the readers through interactional markers. Therefore, studying these genre-specific features of 
interactional metadiscourse markers has gained significance recently. There is a considerable number of cross-linguistic and intralinguistic studies with a focus on metadiscourse markers in various academic genres. These genres cover course books (Crismore, 1983, 1984; Hyland, 1999, 2005; Moreno, 2003), research articles (Abdi, 2002; Dahl, 2004; Hyland, 1996, 2005; Yağız \& Demir, 2015), university student essays (Ädel, 2003; Crismore et. al, 1993; Gardner \& Han, 2018), Master's and PhD theses (Akbaş \& Hardman, 2018; Hewings \& Hewings, 2002; Hyland \& Tse, 2004; Samraj, 2008; Swales, 1990) and newspaper articles (Dafouz-Milne, 2003, 2008). However, studies comparing different genres to reveal how metadiscourse markers might vary from one text type to another are still limited (e.g. Ädel, 2018; Kawase, 2015; Kuhi \& Behnam, 2011). Accordingly, the aim of this study is to investigate the deployment of interactional metadiscourse features in the conclusion parts of two academic genres, that is, research articles and book reviews.

Research articles (RAs) and book reviews (BRs) are two different genres in academic writing, which have different purposes, structures and rhetorical features. As the most prestigious research genre in many disciplines, research articles are scientific texts that report observable facts and the researcher's interpretations of the data (Hyland, 2008, 2011). RAs are believed to be "the pre-eminent genre of the academy" and "the principal site of knowledge making" (Hyland, 2009, p. 67). RAs may present critical reviews and a synthesis of certain topics in a coherent way. They generally follow the macro-structure of introduction-method-results-discussion (IMRD) (Swales, 1990); however, these sections may vary depending on the disciplines (Samraj, 2016, p. 404). Reviewing the existing literature on metadiscourse in research articles show that there are a large number of (cross) disciplinary and (cross) linguistic studies (e.g. Abdi, 2011; Dahl, 2004; Harwood, 2005; Hyland, 1996, 1998, 2001; Vazquez Orta \& Giner, 2008). For example, Hyland (1998) analyzes metadiscourse markers in research articles from different academic disciplines and shows that soft science and hard science writers tend to represent themselves and their research differently through different use of interpersonal features. Abdi (2011) compares different IMRD sections of research articles from social and natural sciences, and finds that social science writers employ more hedges, attitude markers, engagement markers and self-mention while natural science writers employ more boosters in the RD sections.

Found in most academic journals in a relatively less number compared to RAs, BRs are written in order to introduce as well as "to evaluate the scholarly work of a professional peer within the scholarly community" (Lindholm-Romantschuk, 1998, p. 40). A BR is a type of academic writing which describes and critically evaluates a book's structure, content, quality, and its contribution to the field for intended audience. BRs are expected to be critical descriptions and evaluations of a newly published book, and they play a vital role "in scholarship, supporting both the manufacture of knowledge and the social cohesiveness of disciplinary communities" (Hyland, 2000, p. 43). Thus, describing a book without highlighting its evaluative nature would not be complete in a BR. Studies on BRs with a focus on metadiscourse 
have recently begun to appear. One of these studies is by Tse and Hyland (2006a) who find that book reviews include twice as many interactional as interactive markers, and transition markers, engagement markers and hedges represent the most frequent devices of all. They attribute this finding to the evaluative aspect of BRs, as interpersonal concerns are more influential for the writer. Jalilifar et al. (2018) compare book reviews and blurbs written in different disciplines and detect genredependent differences in the use of metadiscourse markers.

Most of the metadiscourse studies were conducted on research articles and its subsections; however, academic book reviews have not been analyzed in relation to their metadiscoursal features adequately. Similarly, how L2 writers of English construct their interactional authorial stance in this particular academic text type has not been investigated yet. The current study intends to bridge this gap by examining the type, frequencies and use of interactional metadiscourse markers in two different academic text types, that is, research articles and book reviews written by L2 users of English. These two academic genres differ not only in their structural forms (i.e. their rhetorical moves) but also in their generic features. Unlike RAs, BRs provide a critical analysis of a book and its author due to their evaluative nature, rather than reporting a completed study. Based on such differences, it is expected that various types of interpersonal markers are employed with different frequencies in these two academic genres. In relation to this assumption, this study attempts to answer the following research questions:

1. What are the types and frequencies of interactional metadiscourse markers used in the conclusion parts of BRs and RAs?

2. Is there any significant difference in the use of interactional metadiscourse in the conclusion parts of BRs and RAs?

\section{Method}

\subsection{Corpus of Book Reviews and Research Articles}

For the purpose of the study, a specialized corpus of BRs and RAs was created. Specialized corpora, which are smaller compared to general corpora, are designed for more specific research goals on a particular variety of language. Such corpora are usually collected for register-specific descriptions and investigations of target languages and becoming increasingly important especially on studies with a focus on non-native speakers' language use. The target texts for this study were selected from different academic journals from disciplines of biology, economy, education, language and literature, law, medicine and politics to capture a wider range of academic knowledge. The choice of these disciplines was guided by the availability of the target texts in the journals and availability of data on the authors and reviewers.

The database of the study consists of 24 research articles and 24 book reviews written by Turkish academic writers of English. The nationality of the authors was identified based on their names, and institutions written in the texts. When in doubt, 
internet search was carried out. The research articles and book reviews constructing the database were published between the years 2004-2016, and each was written by a single author. Each text was coded with its field, followed by author's surname and genre type such as edu_aksoy_ra where "edu" refers to the field of education, "aksoy" is the surname of the author and "ra" stands for research article.

The conclusion parts, where writers/reviewers are more prone to express their ideas, were extracted. In these sections, authors are required to be evaluative and interpretive rather than descriptive. Therefore, interactional metadiscourse markers would be applied more heavily in comparison with other sections of RAs and BRs. In some articles, conclusion parts were merged with discussion sections, in order to avoid any inconsistencies; only those having apparent conclusion sections were selected. BRs, on the other hand, do not have separate titled sections as conclusion. Motta-Roth (1998), who investigated the structural moves of BRs, found that in BRs there is a move, which clearly signals the closing of the review. This is usually the last paragraph of the BRs that serves as the conclusion section. In the corpus collection process of this study, it was ensured that each BR has a concluding paragraph in which the reviewer closes the evaluation of the book. As a result, by cleaning irrelevant parts such as reviewer information, references, titles, as well as authors' names and extracting conclusion sections of the texts, we reached a total number of 12.833 word in our corpus as seen in Table-1.

Table 1. Number of words in the database

\begin{tabular}{lll}
\hline Genre & $\#$ & Word Token \\
\hline Book Reviews & 24 & 3247 \\
Research Article & 24 & 9586 \\
\hline
\end{tabular}

\subsection{Data analysis}

The study employed a corpus-based quantitative and qualitative analysis in which the conclusion parts of two genres were examined. The texts were first uploaded on the corpus analysis software, UAM CorpusTool (O'Donnell 2013), and each text was read and tagged for the linguistic elements signaling interactional metadiscourse. The tool allowed creating a scheme for the marker types and their subtypes. During the annotation procedure the scheme was edited in a cyclical manner. This scheme bases on the taxonomy of interpersonal metadiscourse markers proposed by Hyland (2004, 2005). To clarify the linguistic markers under each macro category, the subcategories of Dafouz-Milne (2003, 2008) was adapted and developed based on the needs of the study (see Table 2). 
Table 2. Taxonomy of Interactional Metadiscourse Markers adapted from Hyland $(2004,2005)$ and Dafouz-Milne (2003, 2008)

\begin{tabular}{|c|c|c|}
\hline Macro category & Subcategories & Examples \\
\hline Hedges: & Modal Auxiliaries & may, might, could \\
\hline \multirow{3}{*}{$\begin{array}{l}\text { Withhold writer's full commitment to } \\
\text { the truth value of the proposition }\end{array}$} & Lexical Verbs & appear, feel \\
\hline & Hedging Adverbs & probably, perhaps, maybe \\
\hline & Hedging Phrases & from my perspective \\
\hline Boosters (Emphatics): & Lexical Verbs & prove, realize \\
\hline \multirow{3}{*}{$\begin{array}{l}\text { Express certainty and emphasize the } \\
\text { force of propositions }\end{array}$} & Boosting Adverbs & evidently, obviously, really \\
\hline & Modal Auxiliaries & have to, must (possibility) \\
\hline & Boosting Adjectives & clear, certain, sure \\
\hline Attitude markers: & Attitude Verbs & agree, prefer \\
\hline \multirow{3}{*}{$\begin{array}{l}\text { Express writer's attitude to } \\
\text { proposition }\end{array}$} & Attitude Adverbs & remarkably, essentially \\
\hline & Attitude Adjectives & shocking, interesting, usual \\
\hline & Attitude Nouns & hope, reason, usefulness \\
\hline Engagement Markers: & Rhetorical questions & $?$ \\
\hline \multirow{4}{*}{$\begin{array}{l}\text { Explicitly refer to or build relationship } \\
\text { with readers }\end{array}$} & Engagement Verbs & consider, note, allow \\
\hline & Asides & 0,1 \\
\hline & Direct address to reader & reader, you, one's \\
\hline & Inclusive expressions & let us, by the way \\
\hline \multirow{3}{*}{$\begin{array}{l}\text { Self-mentions: } \\
\text { Explicit reference to author(s) }\end{array}$} & 1st person singular and plural & I, we, my, our, \\
\hline & pronouns & \\
\hline & Direct address to writer & the writer \\
\hline
\end{tabular}

After making the texts ready to be analyzed with UAM CorpusTool and uploading them to the computer program, the tagging procedure of interactional metadiscourse markers was carried out. The annotation was done in two ways: i) manual and ii) automatic analyses. Manual analysis means reading and tagging markers in each text and automatic refers to searching the markers found in prior studies (Hyland, 2005; Ho \& Li, 2018; Junqueira \& Cortes, 2014; Yağız \& Demir, 2015). Manual analysis was performed by close reading of the texts in order not to miss any potential marker while tagging. After finding the target markers with the help of concordance lines, each potential marker was further analyzed elaborately because the metadiscursive expressions tend to be multifunctional and context dependent. For example, when self mentions (I, we, the author), were further analyzed, it was found that in the language and literature discipline, there were excerpts from poems, which include personal pronouns. Similarly, in BRs, the expression "the author" refers to the author of the book under review. These were excluded since they did not function as metadiscourse markers.

As pointed out by Adel (2006), it can be difficult to make a distinction between metadiscoursal and non-metadiscoursal categories, or to identify its subgroups, since there are some overlaps between metadiscoursal and non-metadiscoursal groups. Three scholars examined the corpus, and the average of three independent data was considered the final data of the study to achieve a higher reliability in the analysis. Because the size of the conclusion sections across the genres is unequal, following 
Crismore et al. (1993), the total number of instances for each category found in each sub-corpus has been normalized per 1000 words. In this way, the comparability of the results was ensured. Significance differences of the normalized texts were calculated automatically using independent-samples $t$-test by the UAM CorpusTool. The results are presented in tables and discussed for each marker.

\section{Results}

To address the first research question, the raw frequencies and the mean frequencies per 1000 words of different types and subtypes of interactional markers were computed across BRs and RAs. The quantitative analysis of the data yielded a total of 753 interpersonal metadiscourse markers in the conclusion parts of BRs and RAs. A cross-genre analysis of the findings reveals that the total number of interpersonal metadiscourse features (normalized per 1000 words) is higher in BR sub-corpus (76.26) than in RA sub-corpus (44.09). This is in line with the previous studies, which demonstrate that BRs comprised significantly more interactional metadiscourse markers (Jalilifar et al., 2018; Tse \& Hyland, 2006a, 2006b). This can be because as earlier studies on the structure of BRs indicated the reviewers postpone their personal evaluation of the book to the conclusion, which is the last move (Gea Valor, 2000; Gezegin-Bal, 2015; Moreno \& Suarez, 2008; Motta-Roth, 1998). Table 3 presents raw frequencies, the density per 1000 words used per interpersonal marker for two genres, and the $t$-test results.

Table 3. Distribution of Interpersonal Markers in BRs and RAs

\begin{tabular}{llllll}
\hline Interactional Markers & \multicolumn{4}{l}{ Book Review Sub-corpus } & \multicolumn{2}{l}{ Research Article Sub-corpus } \\
\cline { 2 - 5 } & Raw & Per 1000w. & Raw & Per 1000w. & TStat \\
Attitude Markers & 171 & 47.42 & 177 & 16.33 & $6.862^{* * *}$ \\
Hedges & 44 & 12.20 & 155 & 14.30 & $4.997^{* * *}$ \\
Boosters & 43 & 11.92 & 99 & 9.13 & 1.715 \\
Self-Mentions & 10 & 2.77 & 33 & 3.04 & 1.862 \\
Engagement Markers & 7 & 1.94 & 14 & 1.29 & 0.307 \\
Total & 275 & 76.26 & 478 & 44.09 & $6.274^{* * *}$ \\
\hline
\end{tabular}

*** There is high significance between groups at $98 \% \dagger$

When the types and frequencies of interactional metadiscourse markers in BRs and RAs were compared, it was found that all interactional marker types were employed with different frequencies and densities in both genres (Table 3). A closer analysis of each category indicated that in BRs, attitude markers (47.42) were the most dominantly used markers followed by hedges (12.20), boosters (11.92), self-mentions (2.77) and engagement markers (1.94). In RAs, although not as outstanding as in BRs, attitude markers (16.33) were the most frequent markers followed by hedges (14.30), boosters (9.13), self-mentions (3.04) and engagement markers (1.29). When BRs and

† This percentage was given by the UAM CorpusTool, $\mathrm{p}<0.02$ 
RAs were compared in terms of the subtypes, there was a high statistical difference in the use of attitude markers. In other words, BRs included about three times more attitude markers, which can be a result of the evaluative nature of BRs as academic text types. The difference in the use of hedges were also found to be statistically significant between two genres as RAs contained remarkably more hedging devices compared to BRs. More detailed explanation of each interactional marker, ranked in a descending order of frequency, will follow.

\subsection{Attitude markers}

Attitude markers generally designate the affective stance of the writer to propositions, conveying surprise, agreement, frustration, obligation, and so on. The findings reveal that attitude markers constituted the most frequently used interactional devices in both datasets contrary to the results of some previous studies (Hyland \& Tse, 2004; Tse \& Hyland, 2006a, 2006b). When compared with RAs, the density of attitude markers in BRs is remarkably higher (per 1,000 words; BRs: 47.42; RAs: $16.33, t=6.862 ; \mathrm{p}<0.02)$ as shown in Table 4 . BRs are more evaluative compared to RAs because in a BR, the reviewer comments on the book under review by positively or negatively criticizing it. The data evidence that while evaluating the book, more attitude markers, which show the personal view of the reviewer, are needed. According to Hyland, attitude verbs, adverbs and adjectives are the most explicit markers displaying attitude, and "this marking of attitude in academic writing allows writers both take a stand and align themselves with disciplinaryoriented value positions" (2009, p. 76). This is also observed in this study; the attitude marker types identified in the data are adjectives, adverbs, modal auxiliaries, verbs and nouns as seen in Table 4.

Table 4. Distribution of Attitude Marker Categories in BRs and RAs

\begin{tabular}{llllll}
\hline Linguistic Markers & \multicolumn{2}{l}{ Book Reviews } & \multicolumn{2}{l}{ Research Articles } & TStat \\
\hline & Raw & Per 1000w. & Raw & Per 1000w. & $5.960^{* * *}$ \\
Attitude Adjectives & 110 & 30.50 & 97 & 8.95 & 0.542 \\
Attitude Adverbs & 13 & 3.61 & 27 & 2.49 & $2.985^{* * *}$ \\
Attitude Verbs & 22 & 6.10 & 15 & 1.38 & $3.174^{* * *}$ \\
Attitude Modal Aux. & 4 & 1.11 & 31 & 2.86 & $4.543^{* * *}$ \\
Attitude Nouns & 22 & 6.10 & 7 & 0.65 & $6.862^{* * *}$ \\
Total & 171 & 47.42 & 177 & 16.33 & \\
\hline
\end{tabular}

$* * *$ There is high significance between groups at $98 \%$

Within the attitude markers category, we observed that attitude adjectives were the most frequently occurring feature in both genres. However, when the two genres were compared, BRs included significantly more adjectives $(t=5.960 ; \mathrm{p}<0.02)$. This can be explained with the distinctive feature of BRs as a genre that require personal evaluation through the use of adjectives and adverbs which carry evaluative meaning (e.g., Conrad \& Biber, 2000; North, 1992). The data of the present study include a number of attitude adjectives that reflect the personal judgment of the writer (e.g. 
magnificent, noteworthy, reasonable, valuable, worthy). Most of the adjectives found indicate how specific genres have particular expectations in regard to metadiscourse markers. Adjectives that help to evaluate a book for the review such as readable, impressive, recommendable, well-written were commonly used in BRs; whereas, they never occurred in RAs. This finding is consistent with Shaw's study (2009) in which the most frequent evaluative words were adjectives. It is apparent that evaluation requires more adjectives describing attitude in $\mathrm{BRs}$ as a genre.

1. It is our belief that this handbook will serve as a valuable resource for efforts to engage in both research and practice... (edu_aslan_br)

2. From this point, this book is a very important resource for professionals and related individuals in early childhood inclusion. (edu_ardic_br)

Similar to adjectives, attitude adverbs were used to express personal evaluation of the writer (e.g. effectively, fluently, poorly, thoroughly) in both genres. Adverbs need to be analyzed elaborately since they can be attitudinal markers or boosters depending on the context. This was reported previously in several studies. For example, Lipari (1996, p. 827) stated that adverbs such as "unfortunately, importantly, happily" express the speaker's affect toward or evaluative judgment of a claim whereas adverbs such as "certainly, obviously and clearly express the speaker's assessment of the truth value or reliability of a claim ..." In our data, there were three occurrences of clearly (two in BRs and one in RAs). According to Hyland's (2005) list of metadiscourse markers, clearly is considered as a booster; however, we found that it may vary according to the context. A detailed examination reveals that in BRs clearly was used as an attitudinal marker by which the reviewer expresses his own view on the book under review as seen in the example of (3). The occurrence of clearly in example (4) from a research article in the corpus; on the other hand, can be considered as a booster, which adds emphasis to the statement.

3. The book is written very clearly and fluently with an expertise that handles the most current discussions of the topic successfully and comprehensively. (lang\&lit_akbulut_br)

4. When examining the [proper name], it can be clearly noticed that the spending levels of the [proper name] for the 2014-2015 period are almost equal. (econ_alkin_ra)

Attitudinal verbs (e.g. benefit, contribute, enable, facilitate, illuminate, recommend) were the third most frequently occurring feature in total. When the two genres were compared, BRs contained significantly more attitude verbs $(t=2.985 ; \mathrm{p}<0.02)$. These verbs showed positive or negative attitude of the reviewer on the book as seen in example (5).

5. I recommend this book to all hematologists and historians and to every beginner of science research. (med_akar_br)

Unlike the other markers, a heavier use of attitude modal auxiliaries was observed in RAs (2.86) than in BRs (1.11). These markers are should, have/has to and must all of which indicate obligation. 
6. Therefore, these studies should be expanded to the other economically important and edible mushrooms. (bio_dogan_ra)

Data for attitude nouns, as the last subcategory, show a substantial difference between the two genres (BRs: 6.10 , RAs: $0.65 ; t=4.543 ; \mathrm{p}<0.02$ ). BRs contained significantly more attitude nouns that manifest the personal assessment of the writer for the book they are reviewing (e.g. addition, contribution, impact, importance, shortcoming, strength).

7. The significant novelty of the book lies in its original approach and alternative solutions to inactive state of Turkish Foreign Policy...(pol_yenigun_br)

\subsection{Hedges}

Hedges are the markers that enable writers to mitigate their authorial voice by conveying partial commitment to the truth-value of the statement. Data analysis shows that hedges stand in the second place among interactional markers in the two corpora and take significantly a larger part in RAs than BRs $(t=4.997, \mathrm{p}<0.02)$. This finding agrees with the previous studies (Abdi, 2002; Hyland, 1996, 1998; Kawase, 2015), which reveal that hedges hold a prominent position among different interpersonal metadiscourse categories in RAs. Kawase (2015), who studied the introduction parts of the articles, proposes that the greater use of hedges in RAs can be considered as a genre-derived feature, since hedges enable writers to be less assertive in describing previous knowledge. Table 5 presents the ranked distribution of the hedges in BRs and RAs.

Table 5. Distribution of Hedge Categories in BRs and RAs

\begin{tabular}{llllll}
\hline & \multicolumn{2}{l}{ Book Reviews } & \multicolumn{2}{l}{ Research Articles } & Tsat \\
\cline { 2 - 6 } Linguistic Markers & Raw & Per 1000w. & Raw & Per 1000w. & $4.159^{* * *}$ \\
Hedging Modal Auxiliaries & 13 & 3.61 & 69 & 6.36 & 1.862 \\
Hedging Adverbs & 10 & 2.77 & 33 & 3.04 & 1.007 \\
Hedging Lexical Verbs & 9 & 2.50 & 23 & 2.12 & 1.125 \\
Hedging Phrases & 4 & 1.11 & 13 & 1.20 & 0.434 \\
Hedging Determiner & 4 & 1.11 & 9 & 0.83 & 0.641 \\
Hedging Adjectives & 3 & 0.83 & 8 & 0.74 & 0 \\
Hedging Nouns & 1 & 0.28 & 0 & 0 & $4.997^{* * * *}$ \\
Total & 44 & 12.20 & 155 & 14.30 & \\
\hline
\end{tabular}

$* * *$ There is high significance between groups at $98 \%$

In general, writers employ hedging markers to make up for the threatening effects of their comments in the conclusion parts. In the data, hedging modal auxiliaries (e.g. can, could, would) were used more frequently in comparison to other hedging markers. RAs were observed to include significantly more hedging modal auxiliaries than BRs $(t=4.159, \mathrm{p}<0.02)$. This finding indicates that in the conclusion sections of RAs, writers favor to tone down their adherence to the proposition as seen in example (8). For Hyland, in science, hedging is mainly "an element of persuasion, enabling 
claims to be expressed with precision, caution and humility and to meet audience expectations of accuracy and negotiation" (1996, p. 261). In this sense, hedging modal auxiliaries help writers to open a space for readers to question interpretations especially in the conclusion parts.

8. The influence of Surrealism and Freudian psychology on some of his poems may further illuminate the misleading impression of arbitrariness in the startling images he concocts. (lang\&lit_oz_ra)

The rest of the hedging markers have a limited use in the data. Hedging adverbs such as personally, about, perhaps are the second most frequently occurring features that the writers preferred to employ in order to downgrade the commitment to their propositions as in example (9). Lexical verbs found in the corpora such as appear, assume, look like, seem, and tend to help to soften the statement of the author and the reviewer as in example (10). As linguistic devices, which are used to refrain from absolute adherence to a proposition, hedging phrases enable the speaker/writer to present information as an opinion rather than a fact (e.g. in a sense, in general, to our knowledge, to some extent) as in example (11). Similarly, hedging adjectives (e.g. possible, unlikely), hedging determiners (e.g. some) and nouns (i.e. belief) were found with a lower density.

9. Dewey's recommendations were generally welcomed, especially those on training village teachers. (edu_uygun_ra)

10. The book seems to handle almost all issues concerning discrimination all over the world in general. (pol_sezal_br)

11. In conclusion, to our knowledge, this is the first study that investigated the knowledge attitudes, and practices about epilepsy among medical students in Turkey (med_kartal_ra).

\subsection{Boosters}

Boosters are commonly used to express the authors' confidence and certainty in what they say, and to indicate involvement with the subject matter and solidarity with their audience (Hyland, 2005, 2009). They highlight collective information and enrollment in a group, whereas they restrict possibilities for alternative voices (Hyland, 2009, p. 75). We expected to find that BRs include more boosters compared to RAs; however, the general density of boosters is similar across genres (surprisingly). In BRs, reviewers need to convey their personal opinions on the readers about the book. They are overtly involved in the subject and we thought that managing this might require the use of boosters as interactive markers. The reason of similar use of boosters in BRs and RAs could be because the data is limited to conclusion sections only, or the writers still do not want to overtly impose their personal opinions on the readers with confidence and threaten their negative face even if the academic genre requires it. Table 6 presents the ranked distribution of the boosters in BRs and RAs. 
Table 6. Distribution of Booster Categories in BRs and RAs

\begin{tabular}{llllll}
\hline Linguistic Markers & \multicolumn{2}{l}{ Book Reviews } & Research Articles & TStat \\
\hline & Raw & Per 1000w. & Raw & Per 1000w. & 2.029 \\
Boosting Adverbs & 30 & 8.32 & 32 & 2.95 & $2.414^{* * *}$ \\
Boosting Modal Auxiliaries & 5 & 1.39 & 26 & 2.40 & 2.267 \\
Boosting Lexical Verbs & 3 & 0.83 & 19 & 1.75 & 0.615 \\
Boosting Determiners & 5 & 1.39 & 12 & 1.11 & 0 \\
Boosting Phrases & 0 & 0 & 8 & 0.74 & 0 \\
Boosting Adjectives & 0 & 0 & 2 & 0.18 & 1.715 \\
Total & 43 & 11.92 & 99 & 9.13 &
\end{tabular}

A further analysis of subcategories shows that both BRs and RAs contained boosting adverbs (e.g. clearly, extremely, exceptionally, fully, highly, obviously) with the highest frequency. However, they did not show difference in their density between the genres.

12. The book is indeed an essential reading for those who are particularly interested in the structure of the housing market in the US ... (econ_barlas_br)

The second most frequent subcategory is boosting modal auxiliary, which included will as the only modal auxiliary. It is used more frequently in RAs $(t=2.414, \mathrm{p}<0.02)$ functioning as a device for strong commitment to the proposition as seen in example (13). Within the hierarchy of epistemic modals, will characterizes the highest degree of certainty. This finding implies that writers of RAs favor this marker more to express confidence over arguments in their conclusions.

13. In conclusion, acquiring new rumen samples from various ruminants in the different areas of the world will provide further knowledge ... (bio_gurelli_ra)

As Hyland argues, while boosters limit possibilities for alternative voices, they also emphasize "shared information and group membership as we tend to get behind those ideas which have a good chance of being accepted" (2009, p. 75). The last four categories of boosters, that is lexical verbs (e.g. prove, demonstrate, shown), boosting determiners (i.e. all), boosting adjectives (e.g. obvious, unquestionable), and boosting phrases (e.g. given the fact that, it is imperative that, as it is known) had a limited use in the data with no significant difference between the genres.

\subsection{Self-mention}

Self-mention refers to the use of first-person pronouns, possessive adjectives and direct references to the writer in order to present information about the writer. It is not always possible for the writers to avoid exhibiting their authorial identities and their stances in the text, therefore an explicit author reference is inescapable most of the time. Findings reveal that there is not a heavy use of self-mentions in the data, and RAs do not differ in terms of their frequency as seen in Table 7. This finding is in line with previous studies (Hyland \& Tse, 2004; Jalilifar et al., 2018; Tse \& Hyland, 
2006a), which reveal that self-mentions were one of the least frequently applied interactional markers. This might be because the data in the corpus is limited to conclusion parts only, and the writers tend to avoid personal interference and to transmit an objective view in the conclusion parts. Additionally, no direct address to the writer was identified in the study, and the items like 'the author' and 'the writer' did not function as self-mentions in the BRs data since they denoted to the author of the book under review not the reviewer.

Table 7. Distribution of Self-Mention Categories in BRs and RAs

\begin{tabular}{llllll}
\hline Linguistic Markers & \multicolumn{2}{l}{ Book Reviews } & Research Articles & TStat \\
\hline \multirow{3}{*}{ 1st Person Pronouns } & Raw & Per 1000w. & Raw & Per 1000w. & \\
Total & 10 & 2.77 & 33 & 3.04 & 1.862 \\
\hline
\end{tabular}

Although all the texts were single authored, first person plural forms (i.e. we, our and $u s$ ) were observed in the data. According to Hyland (2001), these plural forms are far less intrusive, and downplay personal contributions as seen in example (14).

14. It is our belief that this handbook will serve as a valuable resource for efforts to engage in both research and practice in the area of moral development and character education. (edu_aslan_br)

\subsection{Engagement markers}

Engagement markers aim to bring the reader into discourse by overtly addressing readers through centering their attention or involving them as participants in the text via second person pronouns, directives, questions, personal asides, and reference to shared knowledge (Hyland, 2001, 2004). As academic writing presupposes the active role of readers, the engagement of the readers is an essential element in academic texts to ensure writer's argument. Unlike the findings of Tse and Hyland (2006a) that engagement markers are the most prevalent markers among interactional markers in BRs they analyzed, the study reveals that the texts in both genres do not include many engagement markers, and the density of engagement markers was not remarkably similar across genres (Table 8). This can be because the sections included in the study are limited to the conclusion parts.

Table 8. Distribution of Engagement Marker Categories in BRs and RAs

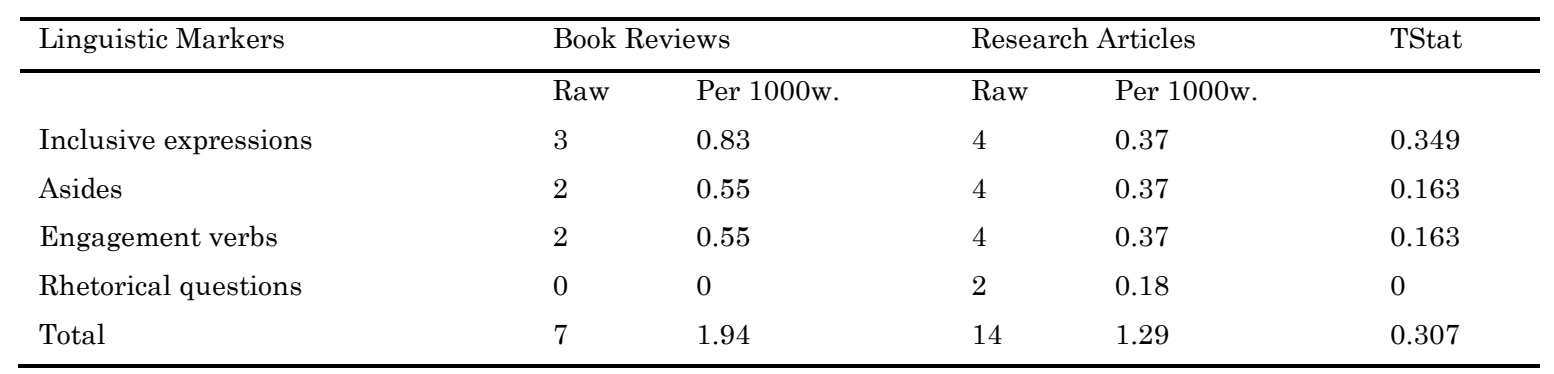


Inclusive expressions such as our, us, let's in the data help the writer to create a bond with the readers, to develop a dialogic atmosphere in the text, and to include them into their point of view by bringing the reader into the discourse stage.

15. The administrators obviously should provide the grounds for freedom of speech, but let's not forget that this freedom will only gain meaning if we have our own unique opinions. (law_kizil_br)

The examples for the subcategory of asides include parentheses and a hyphen, which guide the reader by breaking off the argument to give extra information on what has been said as well as to establish solidarity with the readers.

16. Each species description contains sections on colony diameters, colours and textures, microscopic characteristics, distinguishing features, taxonomic references, habitats and (if present) common synonyms and major mycotoxins. (bio_asan_br)

Engagement verbs identified in the corpus were seen and noted, which enable the writer to build relationship with readers by directing their attention towards critical points in the text. Rhetorical questions and interrogative sentences add a dialogic element to the text and strengthen writer-reader interaction. Two examples of questions were found in RAs subcorpus, which shows that writers do not prefer to ask questions in the conclusion sections of the texts. Both examples are used to leave room for readers to think as a way of arousing readers' interest.

\section{Conclusions}

The goal of this study was to investigate the use of interactional metadiscourse markers in the conclusion sections of BRs and RAs to find out the similarities and differences of linguistic preferences of the authors. The overall finding of the study is that the frequency and type of metadiscourse markers in BRs and RAs are genre dependent. From a contrastive perspective, the total number of interpersonal metadiscourse markers (normalized per 1000 words) in BR sub-corpus outnumbered those in RA sub-corpus. While authors of RAs provide a general summary of the study in the conclusion sections, reviewers of BRs tend to use more interactional markers to conclude their reviews with a more personal and evaluative voice.

In BRs, attitude markers clearly stand out as the most frequently used interactional markers. Reviewers made considerable use of adjectives and adverbs as evaluative markers to conclude their comments on the book and by doing this they "serve the underlying purpose of the genre" (Jalilifar et al., 2018, p. 101). This finding accords with the evaluative nature of BRs since reviewing a book requires evaluation, thus attitudes of the reviewer. Crismore et al. (1993, p. 53) explain attitude markers as markers that "express writers' affective values - their attitudes towards the propositional content and/or readers rather than commitment to the truth-value." As book reviewers need to show their attitudes, indicate their presence and also guide their readers about the book under review, it is expected that BRs include more attitude markers. Additionally, there seems to be a significant difference in the 
variety of attitude markers between two genres of academic writing. BRs include more various, colorful and genre-oriented samples of attitudinal adjectives and adverbs targeting the book's features (i.e. well-written, readable). Based on these differences, we can conclude that genre influences how authors/reviewers construct their academic texts and show their authorial voice. This shows that feelings and sentiments are not absent from academic writing, but their existence depends on the academic genre.

Another significant finding is that a high incidence of hedges was observed in RAs. This can be related to function of the conclusion sections. In these sections, we find comments on the information presented in the articles and summaries of the results as well as claims put forward about the future events. Authors of the RAs needed to use hedges to downtown their voice while closing their texts by accentuating the most important aspects of their work. Hedges cause a statement to be less certain and add some degree of doubt about writers' observations and conclusions. This is not expected in BRs in which a reviewer is expected to express his opinion overtly on the book under review.

The paper provides further support for the view that "metadiscoursal analysis is a valuable means of exploring academic writing and of comparing the rhetorical preferences of different discourse communities" (Hyland, 2004, p. 148). Constructing authorial voice seems to vary according to the genre, and this is realized by the use of certain metadiscourse markers. Creating an awareness of genre conventions for language learners is needed (Holmes, 1997; Swales, 1990). Metadiscourse is not a separate stylistic instrument that authors can diverge as they wish; rather it is closely tied up with expectations of certain academic milieu. In line with this, the findings of the study have some pedagogical implications especially for English for academic contexts. Thus, findings of the study could be used by instructors in these contexts to raise awareness about certain generic features required by different text types, which help to convey authorial stance. By showing that BRs and RAs have their particular markers to construct textual interaction, the study offers constructive implications for teaching EAP/ESP. Further studies still need to be conducted with a larger corpus so that we can have a better understanding of how metadiscourse patterns are employed across different genres and languages. The use of interpersonal discourse markers in different genres deserves more investigation and warrants comprehensive research.

\section{References}

Abdi, R. (2002). Interpersonal metadiscourse: An indicator of interaction and identity. Discourse Studies, 4(2), 139-145.

Abdi, R. (2011). Metadiscourse strategies in research articles: A study of the differences across subsections. The Journal of Teaching Language Skills (JTLS), 3(1), 1-16.

Ädel, A. (2003). The use of metadiscourse in argumentative texts by advanced learners and native speakers of English. (Unpublished $\mathrm{PhD}$ dissertation). Göteborg University, Sweden. 
Ädel, A. (2006). Metadiscourse in L1 and L2 English. Amsterdam/Philadelphia: John Benjamins Publishing Company.

Ädel, A. (2018). Variation in metadiscursive 'you' across genres: From research articles to teacher feedback. Educational Sciences: Theory \& Practice, 18, 777-796.

Akbas, E., \& Hardman, J. (2018). Strengthening or weakening claims in academic knowledge construction: A comparative study of hedges and boosters in postgraduate academic writing. Educational Sciences: Theory \& Practice, 18, 831-859.

Conrad, S., \& Biber, D. (2000). Adverbial marking of stance in speech and writing. In S. Hunston and G. Thompson (Eds.), Evaluation in text: Authorial stance and the construction of discourse (pp. 56-73). New York: Oxford University Press.

Crismore, A. (1983). Metadiscourse: What it is and how it is used in school and non-school social science texts (Report No: 273). Center for the Study of Reading Technical Report, University of Illinois.

Crismore, A. (1984). The rhetoric of textbooks: Metadiscourse. Journal of Curriculum Studies, 16(3), 279-296.

Crismore, A., Markkanen, R., \& Steffensen, M. S. (1993). Metadiscourse in persuasive writing: A study of texts written by American and Finnish university students. Written Communication, 10(1), 39-71.

Dafouz-Milne, E. (2003). Metadiscourse revisited: A contrastive study of persuasive writing in professional discourse. Estudios Ingleses de la Universidad Complutense, 11(1), 29-57.

Dafouz-Milne, E. (2008). The pragmatic role of textual and interpersonal metadiscourse markers in the construction and attainment of persuasion: A cross-linguistic study of newspaper discourse. Journal of Pragmatics, 40, 95-113.

Dahl, T. (2004). Textual metadiscourse in research articles: A marker of national culture or of academic discipline? Journal of Pragmatics, 36, 1807-1825.

Gardner, S., \& Han, C. (2018). Transitions of contrast in Chinese and English university student writing. Educational Sciences: Theory \& Practice, 18, 861-882.

Gea Valor, M. L. (2000). A pragmatic approach to politeness and modality in the book review articles. Valencia: Universitat de Valencia. SELL Monographs. Lengua Inglesa.

Gezegin-Bal, B. (2015). Book review genre in academic writing: A comparative study of English and Turkish across ten disciplines. (Unpublished Doctoral Dissertation). Middle East Technical University, Ankara, Turkey.

Harwood, N. (2005). 'Nowhere has anyone attempted... In this article I aim to do just that': A corpus-based study of self-promotional $I$ and $w e$ in academic writing across four disciplines. Journal of Pragmatics, 37, 1207-1231.

Hewings, M., \& Hewings, A. (2002). "It is interesting to note that ...": A comparative study of anticipatory 'it' in student and published writing. English for Specific Purposes 21, 367-383.

Holmes, R. (1997). Genre analysis, and the social sciences: An investigation of the structure of RA discussion sections in three disciplines. English for Specific Purposes, 16(4), 321-327.

Hyland, K. (1996). Talking to the academy: Forms of hedging in science research articles. Written Communication 13(2), 251-81.

Hyland, K. (1998). Persuasion and context: The pragmatics of academic metadiscourse. Journal of Pragmatics, 30, 437-455.

Hyland, K. (1999). Talking to students: Metadiscourse in introductory coursebooks. English for Specific Purposes, 1, 3-26.

Hyland, K. (2000). Disciplinary discourses: Social interactions in academic writing. London: Longman. 
Hyland, K. (2001). Bringing in the reader: Addressee features in academic articles. Written Communication, 18(4), 549-574

Hyland, K. (2004). Disciplinary interactions: Metadiscourse in L2 postgraduate writing. Journal of Second Language Writing, 13, 112-132.

Hyland, K. (2005). Metadiscourse: Exploring interaction in writing. Oxford: Continuum.

Hyland, K. (2008). Persuasion Interaction and the Construction of Knowledge: Representing Self and others in Research Writing. International Journal of English Studies, 8(2), 1-23.

Hyland, K. (2009). Academic discourse: English in a global context. London: Bloomsbury.

Hyland, K. (2011). Disciplines and discourses: Social interactions in the construction of knowledge. In D. Starke-Meyerring, A. Paré, N. Artemeva, M. Horne, \& L. Yousoubova (Eds.), Writing in Knowledge Societies (pp. 193-214). West Lafayette, IN: The WAC Clearinghouse/Parlor Press.

Hyland, K., \& Tse, P. (2004). Metadiscourse in academic writing: A reappraisal. Applied Linguistics, 25(2), 156-177.

Ho, V., \& Li, C. (2018). The use of metadiscourse and persuasion: An analysis of first year university students' timed argumentative essays. Journal of English for Academic Purposes, 33, 53-68.

Jalilifar, A., Hayati, S., \& Don, A. (2018). Investigating metadiscourse markers in book reviews and blurbs: A study of interested and disinterested genres. Studies about Languages, 33, 90-107.

Junqueira, L., \& Cortes, V. (2014). Metadiscourse in book reviews in English and Brazilian Portuguese: A Corpus-based analysis. Rhetoric, Professional Communication, and Globalization, 6, 88-109.

Kawase, T. (2015). Metadiscourse in the introductions of $\mathrm{PhD}$ theses and research articles. Journal of English for Academic Purposes, 20, 114-124.

Kuhi, D., \& Behnam, B. (2011). Generic variations and metadiscourse use in the writing of applied linguists: A comparative study and preliminary framework. Written Communication, 28(1), 97-141.

Lindholm-Romantschuk, Y. (1998). Scholarly book reviewing in the social sciences and humanities. London: Greenwood Press.

Lipari, L. (1996). Journalistic authority: Textual strategies of legitimization. Journalism \& Mass Communication Quarterly, 73(4), 821-834.

Moreno, A. I. (2003). Matching theoretical descriptions of discourse and practical applications to teaching: The case of causal metatext. English for Specific Purposes, 22, 265-295.

Moreno, Ana I., \& Suarez, L. (2008). A framework for comparing evaluation resources across academic texts. Text \& Talk, 28(4), 501-521.

Motta-Roth, D. (1998). Discourse analysis and academic book reviews: A study of text and disciplinary cultures. In I. Fortanet, S. Posteguillo, J. C. Palmer \& J. F. Coll (Eds.), Genre Studies in English for Academic Purposes (pp. 29-58). Castelló: Universitat Jaume I.

North, S. M. (1992). On book reviews in rhetoric and composition. Rhetoric Review, 10(2), 348363.

O’Donnell, M. (2013). UAM Corpus Tool (Version 2.8). Madrid: Universidad Autónoma de Madrid.

Samraj, B. (2008). A discourse analysis of Master's theses across disciplines with a focus on introductions. Journal of English for Academic Purposes 7(1), 55-67.

Samraj, B. (2016). Research articles. In K. Hyland \& P. Shaw (eds), The Routledge handbook of English for academic purposes (pp. 403-415). London/New York: Routledge. 
Shaw P. (2009). The Lexis and Grammar of Explicit Evaluation in Academic Book Reviews, 1913 and 1993. In: Hyland K., Diani G. (eds) Academic Evaluation. Palgrave Macmillan, London

Swales, J. (1990). Genre analysis: English in academic and research settings. Cambridge: CUP.

Thompson, G. (2001). Interaction in academic writing: Learning to argue with the reader. Applied Linguistics, 22(1), 58-78.

Tse, P., \& Hyland, K. (2006a). 'So what is the problem this book addresses?': Interactions in academic book reviews. Text \& Talk 26(6), 767-790.

Tse, P., \& Hyland, K., (2006b). Gender and discipline: Exploring metadiscourse variation in academic book reviews. In K. Hyland \& M., Bondi (Eds.), Academic Discourse across Disciplines, (pp. 177-202). Bern: Peter Lang.

Vazquez, I., \& Giner, D. (2008). Beyond mood and modality: Epistemic modality markers as hedges in research articles: A cross disciplinary study. Revista Alicantina de Estudios Ingleses, 21, 171-190.

Yağı, O., \& Demir, C. (2015). A comparative study of boosting in academic texts: A contrastive rhetoric. International Journal of English Linguistics, 5(4), 12-28.

\section{Copyrights}

Copyright for this article is retained by the author(s), with first publication rights granted to the Journal.

This is an open-access article distributed under the terms and conditions of the Creative Commons Attribution license (CC BY-NC-ND) (http://creativecommons.org/licenses/by-nc-nd/4.0/). 